\title{
The genesis of the Schaeffler diagram in the history of stainless steel
}

\author{
Pierre Guiraldenq ${ }^{1}$ and Olivier Hardouin Duparc ${ }^{2, *}$ \\ ${ }^{1}$ École centrale de Lyon, 163 BP, 69134 Écully, France \\ 2 LSI, CNRS-CEA-École polytechnique, 91128 Palaiseau, France
}

Received: 19 May 2017 / Accepted: 18 July 2017

\begin{abstract}
The Schaeffler diagram is regarded through a historical perspective in order to review Anton Schaeffler's life (1919-2001) and to analyze the genesis of the famous structural abacus that made him known throughout the world and still serves as a reference today. The equivalence coefficients of addition elements complementary to chromium and nickel, either alpha formers or gamma formers, were at the heart of the subject. The crystallographic structures of many standard steels, and hence several of their mechanical properties, can be partly predicted before manufacturing on the sole basis of their chemical compositions. A chronological review helps to understand the creative work that was done during this initial research.
\end{abstract}

Keywords: steel welding / heterogeneous bonding / stainless steel coating / chromium and nickel equivalents / dilution line / structural compatibility

The Schaeffler diagram has been frequently used and cited for nearly 70 years. It keeps its importance and freshness in the forecasting of welding operations of steels and in the implementation of complex boiler assemblies. It has been an inspiration for many other works in order to specify the action of addition elements, complementary to chromium or nickel, and it is frequently presented in many reference books in materials science for engineering students and engineers. The chemical additions can thus be interpreted on the basis of the notion of equivalence coefficients, an overall concept that helps the choice of the steel grades to use in the production of optimized workpieces for nuclear industry, chemical industry, shipbuilding, aeronautics, etc. The concept also exists for titanium alloys for instance (aluminium versus molybdenum equivalent contents, respectively for $\alpha$-stabilizers versus $\beta$-stabilizers).

The aim of this presentation is to tell the story of its inventor, Anton Schaeffler (1919-2001), and of his first research work, when he tackled the subject at the end World War II as a young engineer. We will see that, of course, the idea had ancestors, Benno Strauß and Eduard Maurer in Germany, and that the emergency of Schaeffler's famous diagram is also due to contributions of other engineers such as Royal David Thomas Jr (1915-2008), working in the same company where he was employed, viz the Arcos Corporation.

\footnotetext{
* e-mail: olivier.hardouinduparc@polytechnique.edu
}

\section{Anton Schaeffler's life and industrial career}

Anton Schaeffler was born on 19 June 1919 in Milwaukee, Wisconsin, on Lake Michigan (USA). He was educated there until 1944, and particularly at the Catholic Marquette University where he got his BS degree at the end of 1942.

From 1938 to 1942, like many American students, he was an alternate student-trainee in industry, employed by the Harnischfeger Corporation in Milwaukee, learning about heat treatments, chemical controls and metallography. This factory, specialized in the production of welding electrodes, was actively involved in the American war effort.

From 1942 to 1944, Anton Schaeffler prepared a Master of Science degree, working at the same time with the A.O. Smith Corporation, a company that was specialized in mechanical applications and gun production.

His research work for his MS degree dealt with the deposition of stainless steel coatings and his report was entitled: "The investigation of microstructures of single bed chromium-nickel austenitic weld deposits on S.A.E. 4340 + V stock" [1].

It was approved on February 25, 1944 by his Professor of mining and metallurgy, E.R. Shoney, and his thesis defense at the University of Wisconsin-Madisson is dated June 28, 1944, just after the beginning of the big military operations of the Allied Armies in Normandy. Yet, no work 


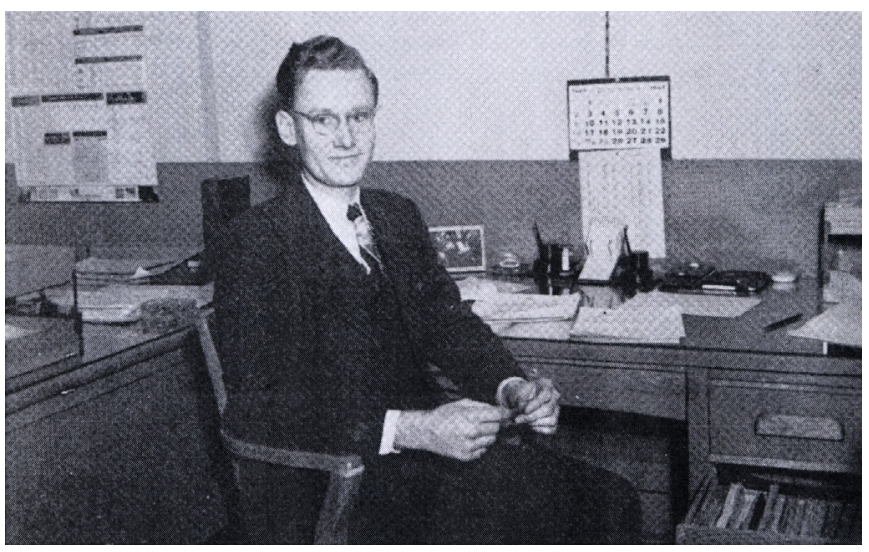

Fig. 1. Anton Schaeffler in his research laboratory with the Arcos Corporation - Philadelphia (Arcos Dippings Journal, 5 [1946]).

was published at that time, probably for reason of Defense and also maybe because the work was not especially original.

Anton Schaeffler kept on his professional activity as Chief Metallographer of the Smith Corporation until the end of 1944, when he came to attend a talk given by Royal David Thomas Junior during a meeting organized by the American Welding Society (AWS) in Milwaukee.

Impressed by the wide culture and the extensive experience of the speaker, Schaeffler got in touch with him and sought a new job as an engineer at the Arcos Corporation. He moved to Philadelphia at the beginning of 1945, cf. Figure 1.

Royal David Thomas Jr gave Schaeffler a succinct technical program corresponding to the urgency of specific controls of the welding procedures with a rigorous classification of metallographic structures that are obtained during these joining operations. That purely technical program was indispensable because the war was not over yet.

The problem was complex because it was related with the bonding of low-alloyed steels to different austenitic stainless steel grades. These welding operations introduced practical difficulties because, in most cases, many cracks appeared resulting in bad mechanical properties and important production rejections occurred.

A rigorous procedure for an efficient running job with a micrographic control of the structures by optical microscopy was finally defined, with a ferromagnetic control of the delta ferrite, which was always present. The microstructures were then correlated with the chemical and spectroscopic analysis of each element found near the welding junction. X-ray diffraction was not widely used at the time to identify and measure the presence of phases like austenite, ferrite, martensite, bainite and carbides in the welding zone. There were only a few laboratories in the world pioneering in this type of research in Materials Science. Information was published in the monthly Journal of Arcos Corporation named "Arcos Dipping" [2]. "Tony" this surname was given to Anton Schaeffler by his colleagues at Arcos - was very friendly and helpful to anybody, giving lessons to technical groups in the factory. He was also passionate about his new city, Philadelphia.
Married in July 1945, he used his free time travelling with his wife, also a native of Wisconsin, and discovered each section of the old city, taking pictures and imagining he could prepare a "Philadelphia Guide Book". This ancillary activity shows that metallography, applied to the morphologies of the crystalline phases of a steel, is never far from the artist's reverie and gaze on Nature. This long time passed with the Arcos Company, five years of his professional activities, was for Anton Schaeffler the peak of his creativity to generate the diagram that bares his name.

From 1950 until the end of his career in 1982, he was a research engineer in a new metal working company, always at the welding service, Allis-Chalmers Corporation in West Allis, Wisconsin, thus returning to the region of his youth. He went on with managerial work in technical development, opening activities for new programs and products standardisation.

He became a Member of the American Society for Metals, as a natural consequence of his engineering career. He was author or co-author of 70 papers, the first three being the background of his creative job with a unique international reputation. He was distinguished on various occasions, by the Tau-Beta-Pi and Alpha-Sigma-Mu honor societies, the Engineering Knights of Marquette, and finally as a Fellow of AWS at the age of 76, with an honorary complimentary mention: "has served the welding community and industry with great distinction ... with the development of the Schaeffler diagram, the first to predict the austenite-ferrite balance in stainless steel weld metals, which is still in wide use to day..." [3].

At the end of his career, some new technics gave him the opportunity to return to his first unique activity. The welding process of stainless steels by laser sources, in relation with his diagram showed that his map can be applied in new welding operations. He gave a short synthesis of his research spirit in a manuscript document prepared with the help of several colleagues in 1991, closing his report with a remark regarding the time spent with Arcos Corporation and Royal David Thomas Jr: "Stainless steels had gotten into my blood" [4].

Anton Schaeffler died on 9 December 2001 at the age of 82 in the Wisconsin where he was born and where he had retired with his family [5].

\section{Genesis of the Schaeffler diagram: 1942-1949}

We present the successive stages of the experimental work carried out by Anton Schaeffler from his Master's thesis until the end of his activities at the Arcos Corporation.

\subsection{Master's degree at the Wisconsin University (1942-1944)}

We have seen in Section 1 that his Master's thesis work implied several periods with two welding electrode manufacturers, Harnischfeger Company and A.O. Smith Corporation. The study covered five grades of stainless steels (AISI 302, 308, 309, 317, 347) deposited in a single pass on structural steel plates of $4340+\mathrm{V}$ (Vanadium) grade. 
The welding operation was manual with an electric arc under low tension and high intensity, with no preheating of the substrate and at a speed of $15 \mathrm{~cm} /$ minute. The electrodes were $5 \mathrm{~mm}$ in diameter. The different physical factors were fixed and controlled in order to minimize the dispersion effect on microstructures.

After deposition of grades, localized samples were taken for chemical analyses and other parts containing the interface between the substrate and the layer were prepared for microscopic observations and microhardness measurements. The intermediate dilution zone was then assessed by measuring the areas corresponding to the bead of the deposited metal (surface side) and the underlying remelted base metal. Schaeffler appreciated the structural evolution on both sides of this zone (at magnification 500) after a chemical etching of the polished surfaces with a solution of nitric acid in ethyl alcohol (Nital) for the base steel side and an aqueous solution of ferric chloride and nitric acid on the side of the deposited stainless steel.

The recognition of the crystalline phases (austenite, ferrite, martensite, possible carbides precipitated on cooling), was then interpreted by the well-known morphological analysis of each of them.

To sum up, the program consisted in comparing five grades of stainless steels well deposited, first in the as-cast state deposition and again after various heat treatments (relaxation at low temperature, quenching after austenitisation and also recovery), thanks to a laborious and repetitive laboratory procedure.

At that time, however, in order to evaluate the presence of the (ferromagnetic) delta ferrite phase of first solidification, Schaeffler only had a pseudo-binary "18-8-carbon diagram" (up to 0.4 weight per cent carbon) corresponding to the work done by Kinzel and Franks in 1940 [6]. He also took advantage of other references: the book of O.H. Henry and G. E. Claussen (1940) for stainlesss steel welding [7], J.H.G. Monypenny's work (1926) [8], some papers in the Welding Journal (1939-1940), and the 1942 Welding Handbook.

The conclusions of Schaeffler's Master thesis are only of industrial interest, showing the role played by the various elements of addition with respect to the formation of carbides, for example Niobium (called Columbium) and the elimination of residual stresses by thermal relaxation treatments. It also draws attention to the diffusion of carbon from the base metal to deposited layers under the effect of a relatively long heat treatment at high temperature. But the problem of the mechanism of formation of delta ferrite, resulting from the liquid-solid transition, which still exists in the "as-cast" state, was not addressed.

These results were far from what was expected in the future by the Arcos Corporation, namely the drawing of a predictive chart of the phases obtained on a heterogeneous welded joint between a structural steel and a stainless steel, by the simple knowledge of chemical compositions. Yet, it was a good starting point for further analysis at Arcos Corp where he was hired.

\subsection{Schaeffler's work at Arcos until 1947}

Anton Schaeffler benefited from Arcos' wide experience and know-how since predecessors had studied the effects of

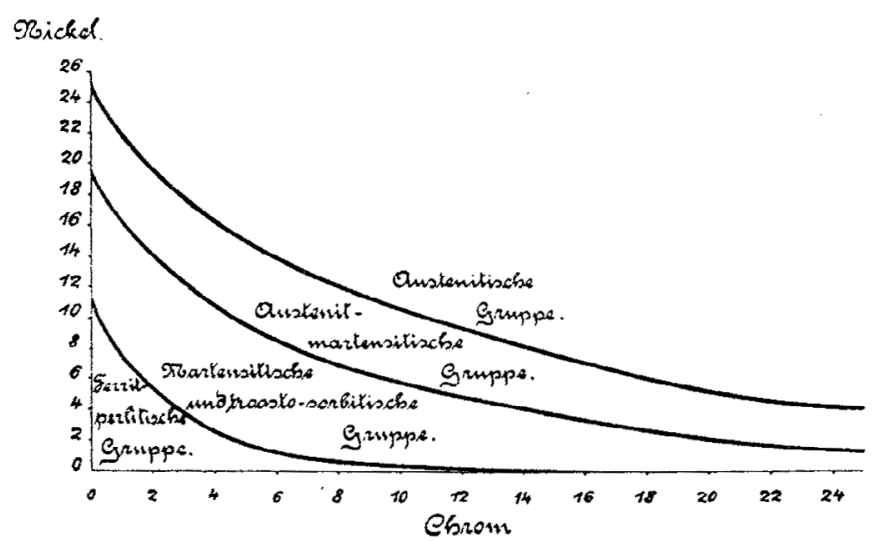

Fig. 2. Strauß and Maurer Diagram for microstructures of steels with chromium and nickel [10].

welding dilution on the mechanical properties of many component parts such as landing gears of the Boeing B-29 fortresses and the C-47 Douglas skytrains, fighter aircrafts (Lockheed P-38 and P-51), armour plates (with manganese addition) of M4 Sherman tanks, US Navy ships, etc...

In a paper presented for the Arcos Corporation at the $28^{\text {th }}$ Annual Congress of the AWS held in Chicago in October 19, 1947 and published in the Welding Journal Research Supplement [9] he gratefully acknowledged the help and contributions of R. David Thomas Jr, his manager and research director, and Hallock C. Campbell, vicepresident of the Arcos Corporation.

A rich technical documentation certainly available at Arcos had allowed Schaeffler to discover earlier German work like that of Strauß and Maurer in Germany (1920) $[10]^{1}$, cf. Figure 2, supplemented by that of Scherer, Riedrich and Hoch published in 1939 [11], cf. Figure 3, which graphically describes the domains of existence of possible crystal phases when nickel and chromium are added to an iron base, with nickel content as the $\mathrm{y}$-direction, and chromium content as the x-direction. This first graph served as the basis for Schaeffler's development of the celebrated Schaffler diagrams.

The work of Strauß and Maurer was also presented in Monypenny's famous 'Stainless Iron and Steel' 1926 book [8], which gives a synthesis of these new highly alloyed steels. Monypenny recalled Léon Guillet's research at the beginning of the century (1905) on the stability of crystalline phases when chromium and nickel are added to the base metal. Guillet was the first to introduce the notion of "equivalence coefficient" for the elements of addition to ferrous and cuprous alloys [12].

Schaeffler also took into account empirical relationships established by Newell and Fleischman [13], Thomas [14], Campbell and Thomas [15], Ostrom and Thomas [16], Field, Bloom and Linnert [17], who proposed several equivalence coefficients to ferrite and austenite stabilizers. The latter authors had proposed a classification

\footnotetext{
${ }^{1}$ It is a pity to have to say that E. Maurer later denounced his colleague to the Gestapo. Benno Strauß died in 1944.
} 

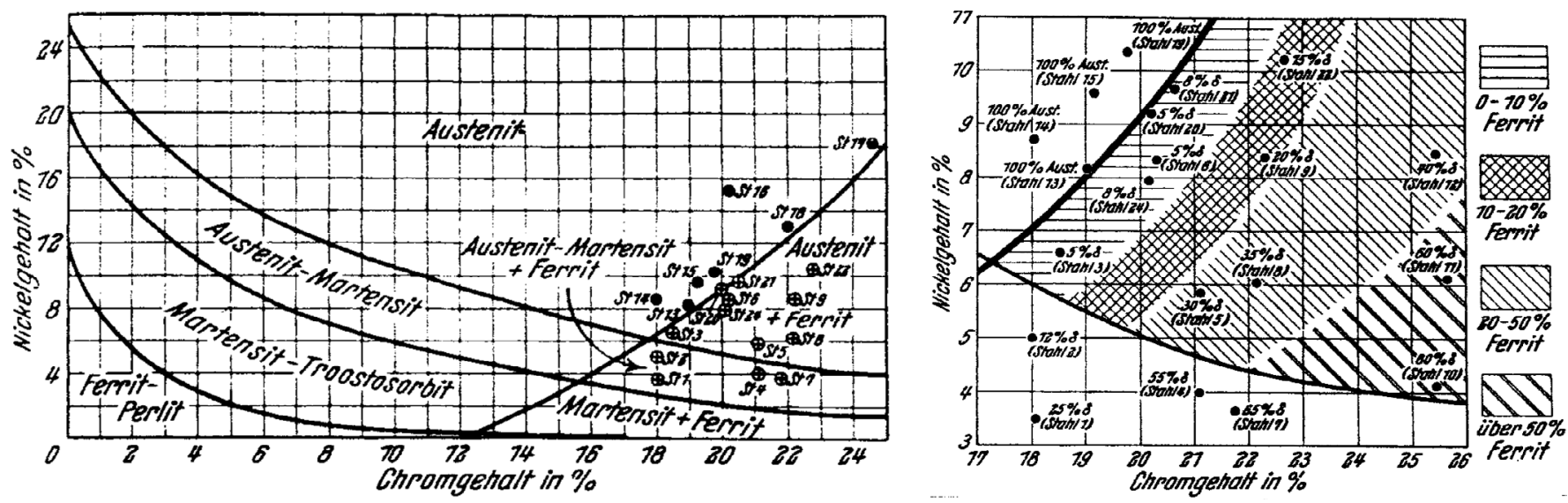

Fig. 3. Graphs of Scherer, Riedrich and Hoch [11], derived from the Strauß and Maurer Diagram.

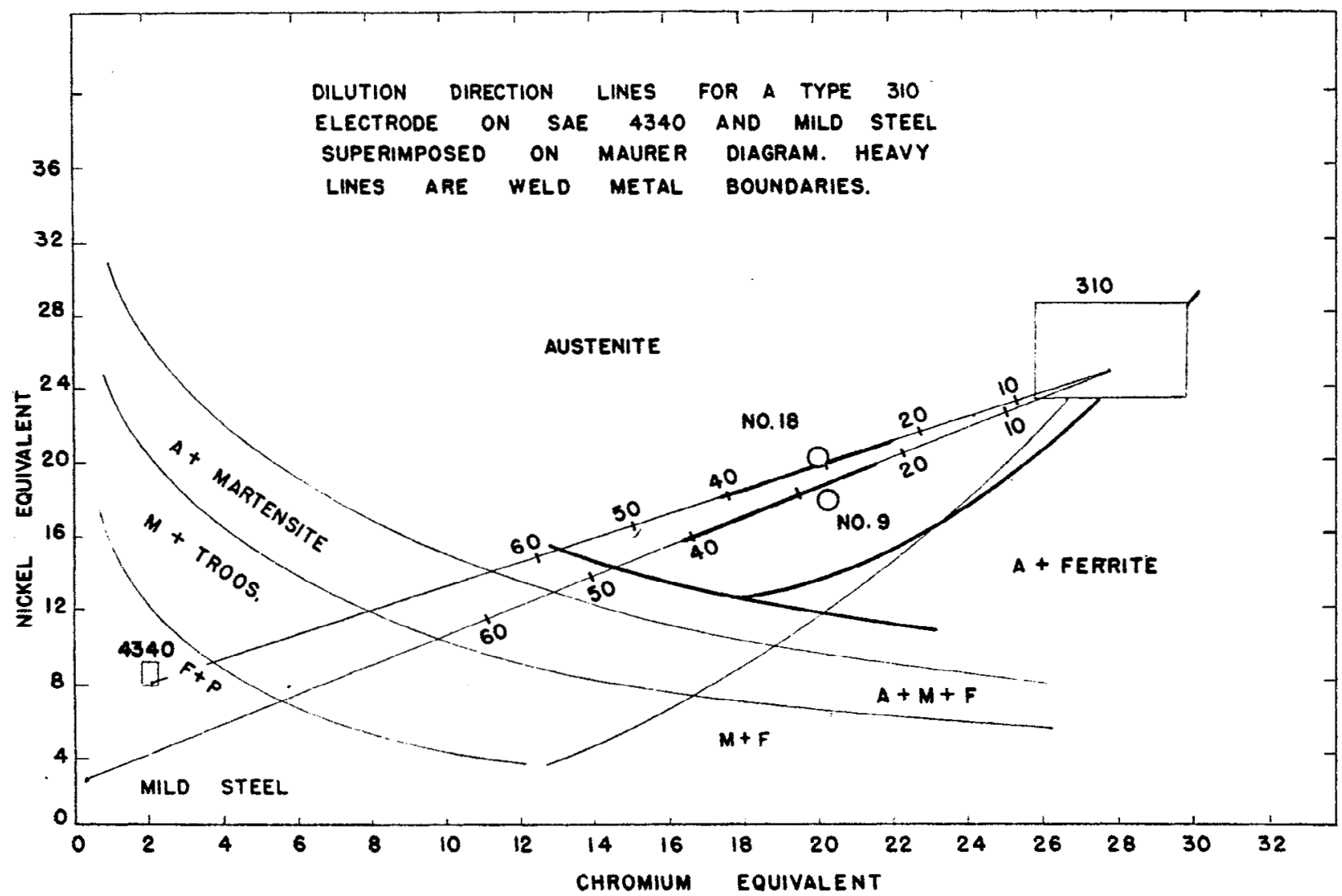

Fig. 4. Example of the Strauß and Maurer Diagram used at the beginning by Schaeffler for his first publication [9].

in two families (the concentrations being in weight) since 1943:

- for austenite stabilizers, with nickel as reference: $\mathrm{Ni} \%+0.5 \mathrm{Mn} \%+30 \mathrm{C} \%$ (Copper, a modest austenite stabilizer, was not included);

- for ferrite stabilizers, with chromium as reference: $\mathrm{Cr} \%+2.5 \mathrm{Si} \%+1.8 \mathrm{Mo} \%+2 \mathrm{Cb} \%$ ( $\mathrm{Ti}$, a carbide former element, was not included. $\mathrm{Cb}$ stands for columbium, usually called $\mathrm{Nb}$ ).

Keeping the representation of the graph of Strauß and Maurer, Schaeffler graphically positioned the crystal phases corresponding to the different families of electrodes, thus surpassing by a giant step the strict framework of his Master thesis (with the stainless steel grades AISI: $307,309+\mathrm{Nb}$, $310,312,316$ ) and three support base steels (an ordinary $0.2 \%$ carbon steel, 4340 steel, already mentioned, and Timken $16 \mathrm{Cr} \%+25 \mathrm{Ni} \%+6 \mathrm{Mo} \%$ ): each representative point in the Strauß and Maurer diagram makes it possible to visualize and predict the corresponding crystal structure obtained at ambient temperature after cooling, following the welding of the metal deposited on the steel substrate.

Figure 4 gives an example of a Strauß-Maurer graph made by Schaeffler, with the description of the filiation 


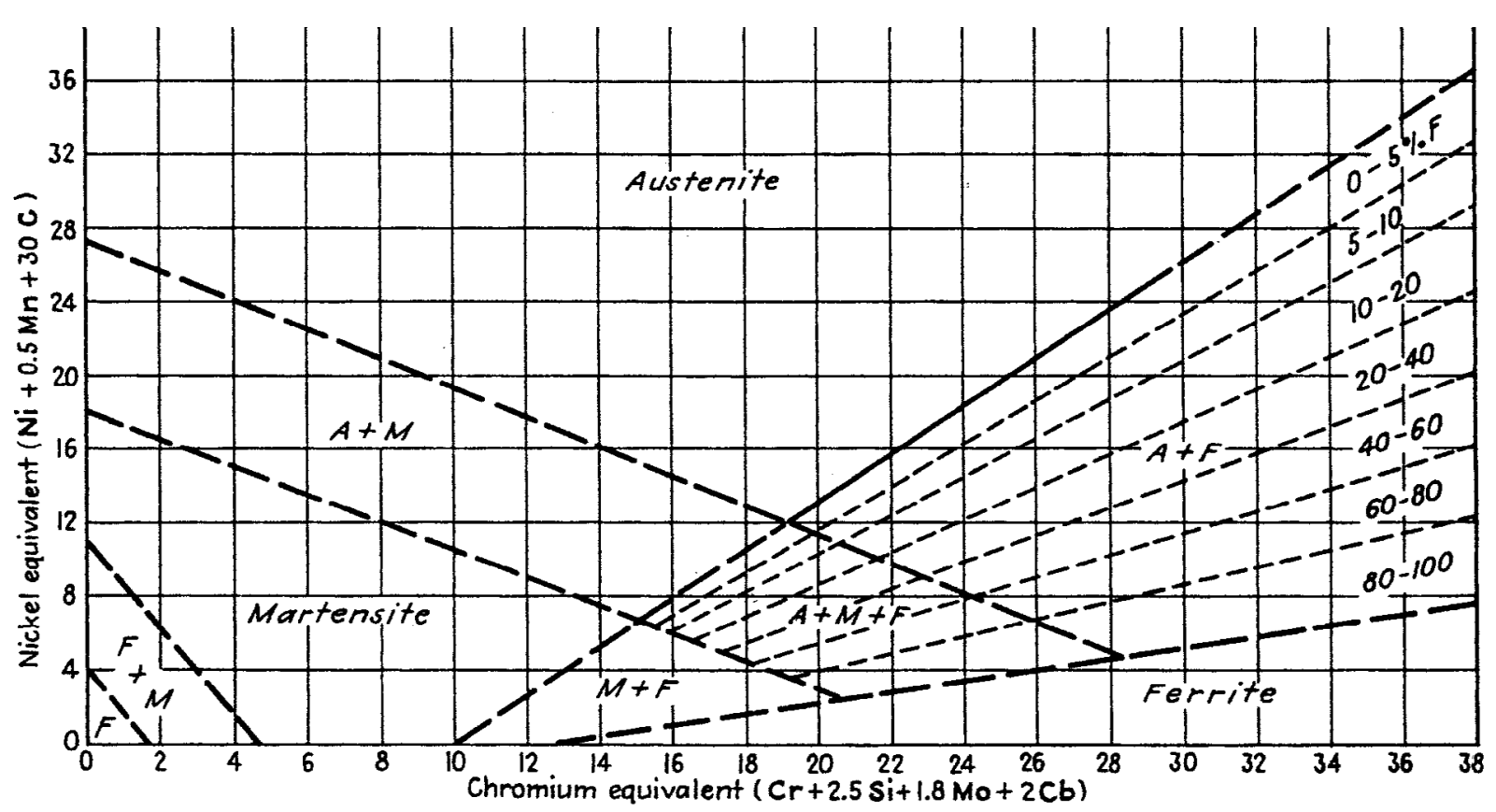

Fig. 5. First Schaeffler Diagram published in 1948 [18].

between base metal and deposition, using a "dilution line" that connects the two extreme representative points of each component (Stainless steel 310-base steel 4340): this line, which was designed by Royal David Thomas Jr, identifies intermediate structures (resulting from chemical concentration gradients due to dilution) with the possibility of estimating them as a volume percentage. Schaeffler concluded his 1947 paper in the Welding Journal [9] by saying that "these figures may be used to guide the engineer in making his first approximation of the structure and composition of dissimilar metals welds."

\subsection{Final architecture of the abacus and its practical interest, as published in Iron Age (1948) [18] and in Metal Progress (1949) [19]}

Schaeffler continued his laborious work and classification of new grades derived from the first stainless steels and, in July 1948 in Iron Age magazine, he published the quasidefinitive version of his diagram. This graph contains different areas that are separated by hyphenated lines corresponding to one or more crystalline phases present at $20^{\circ} \mathrm{C}$, cf. Figure 5. Only one full straight-in (i.e. not dashed) segment is drawn, at the limit between the upper austenite (A) zone and the duplex "austenite + ferrite" $(\mathrm{A}+\mathrm{F})$ zone on the right. This full straight-in segment represents the region where Schaeffler probably analyzed the beginning of ferrite germination during the welding solidification more carefully, in relation to the cracks caused by thermal stresses during cooling. This boundary is to be considered as an important marker for austenitic stainless steels that are called "balanced", because their composition is exactly at the limit $(\mathrm{A} / \mathrm{A}+\mathrm{F})$. This boundary, however, is valid only for weld beads corresponding to the deposition protocol chosen by Schaeffler, i.e. cooled at the same speeds and in volumes of comparable materials. These values have disturbed a large number of users who had not followed the same procedures.

A third publication in Metal Progress in November 1949 finalized and summarized the work of Schaeffler at Arcos in only two pages [19]. This document ended up being the most frequently cited reference in the technical literature for heterogeneous welding. The abacus is plotted with solid lines, see Figure 6, adjusted at the endpoints for the two axes "Ni equivalent" and "Cr equivalent". Schaeffler confirms that for most of the common compositions (AISI: $308,309,309 \mathrm{Nb}, 310,312,316,317,318)$, this diagram is reasonably accurate for estimating the microstructures, with a prediction error for the ferrite content in the $(\mathrm{A}+\mathrm{F})$ zone of the order of $\pm 4 \%$.

\subsection{Extended developments after 1950}

Much later, in the memorandum summarizing his professional career written in 1989 and completed in 1991 [4], Schaeffler did not seek to detail or explain the different parts that composed his own "structural mosaic", as he called it. He only provided his readers with the chronology of his work and insisted instead on the important place occupied by his three colleagues, Field, Bloom and Linnert (referred to by the acronym "Floomert"), for the choice of the numerical equivalents that characterize the principal chemical additions to steel. He also expressed his regrets for not having properly defined the role of nitrogen as an addititive element to steel.

He mentioned the work undertaken by William Thomas DeLong [20] who, in 1960, took into account the presence of nitrogen either as an element of addition or as a residual element, causing a translation of the $\mathrm{A} / \mathrm{A}+\mathrm{F}$ limit line in the abacus, cf. Figure 7 . DeLong gave nitrogen a nickel 
Constitution Diagram for Stainless Steel Weld Metal By Anton $L$. Schaejler

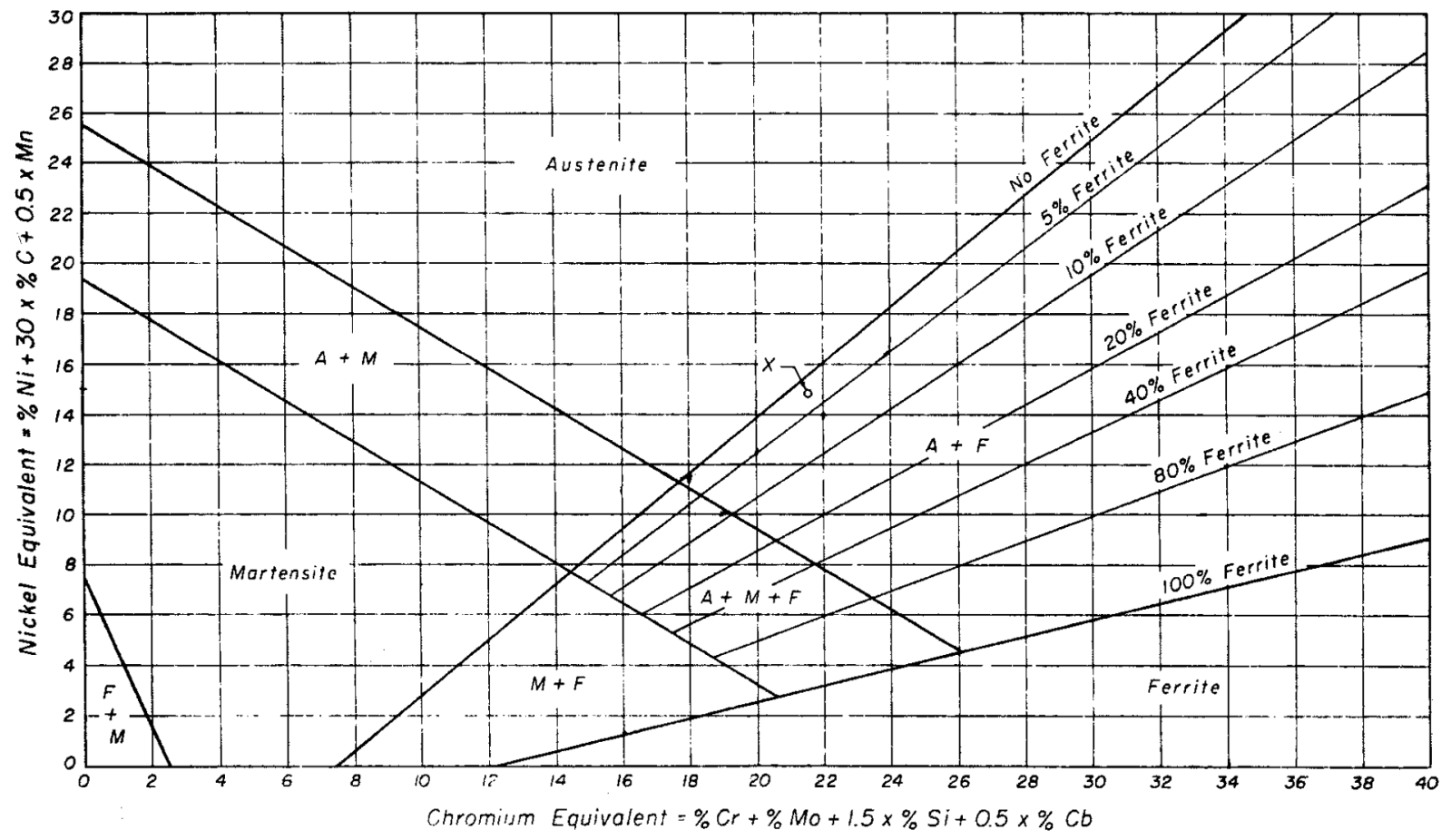

Fig. 6. Second and final Schaeffler Diagram for practical welding operations with stainless steels [19].

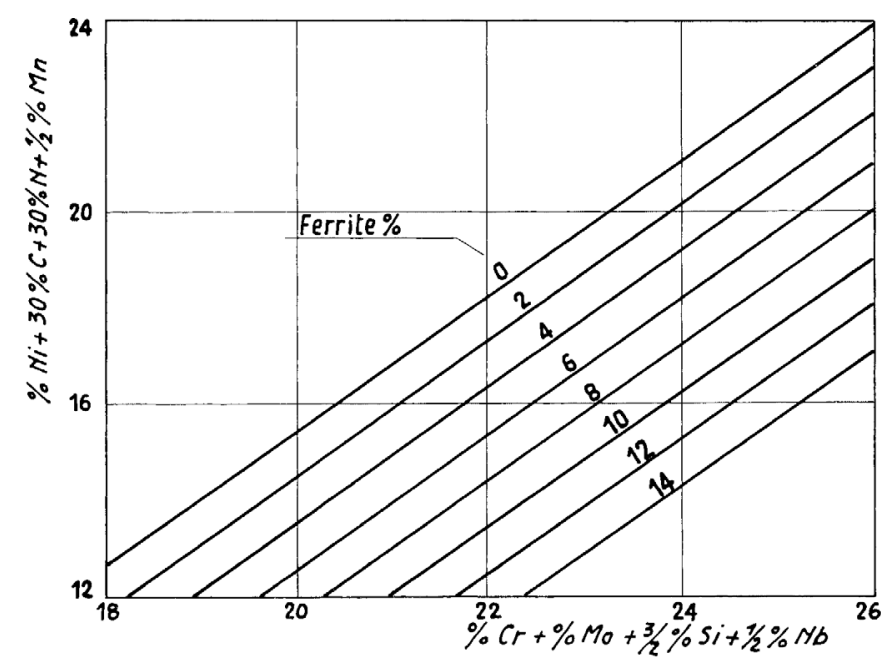

Fig. 7. DeLong's revised section of the Schaeffler Diagram to analyze ferrite content with nitrogen added to the nickel equivalent [20].

equivalence coefficient equal to 30 , as for carbon. Yet we know that these two elements do not have the same effect on the final metallographic structure to stabilize austenite.

Schaeffler said nothing about the interest shown in his diagram by stainless steel producers to predict the structures of massive molded parts, or during high temperature processes (forging, rolling of cast ingots), during which residual ferrite is a factor reducing the hot plasticity of austenite. Other equivalence coefficients may be found with some non-equilibrium structures and the boundary lines of the diagram are displaced, as pointed out by Pryce and Andrews in 1960 [21] and by Guiraldenq in 1967 [22].

In 1998, M.C. Balmforth and J.C. Lippold at the University of Ohio provided in 1998 a complementary analysis to the field of martensitic stainless steels (containing delta ferrite, $\mathrm{A}+\mathrm{M}+\mathrm{F}$ ), with very different coefficients of equivalence and higher for alpha elements [23]. Finally, one can note that the structural domain of combined martensite and austenite $(\mathrm{A}+\mathrm{M})$ simply defined by Schaeffler as two parallel straight lines below the austenite domain, looks like drawings of hardenability of low alloyed steels in function of alloying and quench temperature. Schaeffler never commented on this analogy despite the role it plays for the welding processes in many mechanical applications.

\section{The role of Royal David Thomas, Sr and $\mathrm{Jr}$, and the Arcos Corporation}

We already explained in Section 1 how Anton Schaeffler came to meet R.D. Thomas Jr by the end of 1944 and, in Section 2.2, how he subsequently discovered the Arcos Corporation general knowledge and know-how.

We must naturally also mention R.D. Thomas Sr, cf. Figure 8. R.D. Thomas Sr graduated in Mechanical Engineering at Cornell University in 1919, and created his own firm in Philadelphia, the "R.D. Thomas and Co.", for steelmaking, heat treatments and welding electrodes. Another similar company was established in Philadelphia in 1931, under a license from "la Soudure électrique 


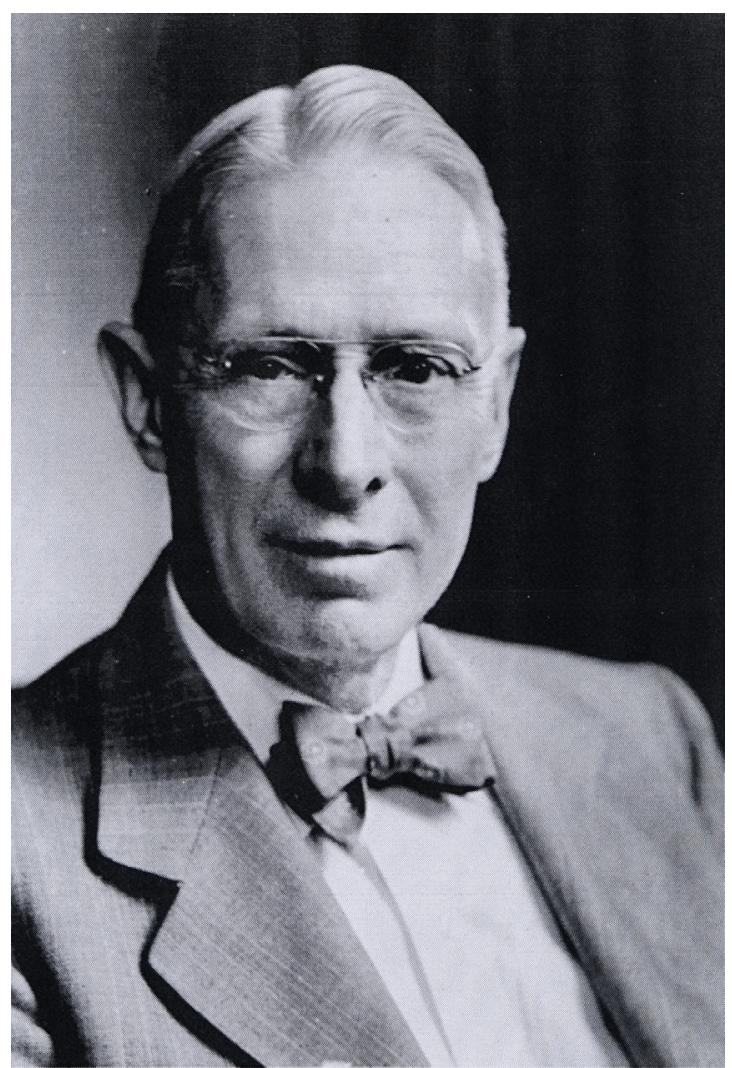

Fig. 8. Royal David Thomas Sr, President of Arcos Corporation - Philadelphia, during and after World War II (family collection, with permission).

autogène" in Brussels, using the trade name "Arcos". Joining this company, R.D. Thomas became its Vice President, and then the President of the Arcos Inc., the result of the merger of the two Philadelphia-based companies. Throughout WWII, Arcos was the only US electrode producer that continued to produce electrodes by the dipping process and this process is included in the name given to the Journal of the company: "Arcos Dippings". R. D. Thomas had also been a charter member of the American Welding Society founded just after WWI in 1919 and President of its local Pennsylvania State section.

Royal David Thomas Jr (Fig. 9) was born in 1915. R.D. Thomas Jr graduated in Chemical Engineering at Cornell University with a work about welding, entitled: "Reactions in electric arc welding." When Tony Schaeffler candidated for the "Dave group" at the end of 1944, David, or Dave, was the "Research and Development Director" of Arcos, after time spent as a metallurgical engineer. He had many patents on the subject (the number of steel standards proposed by AWS and coming from Arcos for industrial needs increased by a factor 2 between 1937 and 1945).

"Arcos Dippings" published many details about the life of engineers during the War, especially those who, among others, were fighting all over the world, first in the Pacific Ocean and then in Europe. The mails these engineers sent from the battle areas, or during their military hospital convalescence, gave the opportunity to deeply link them to

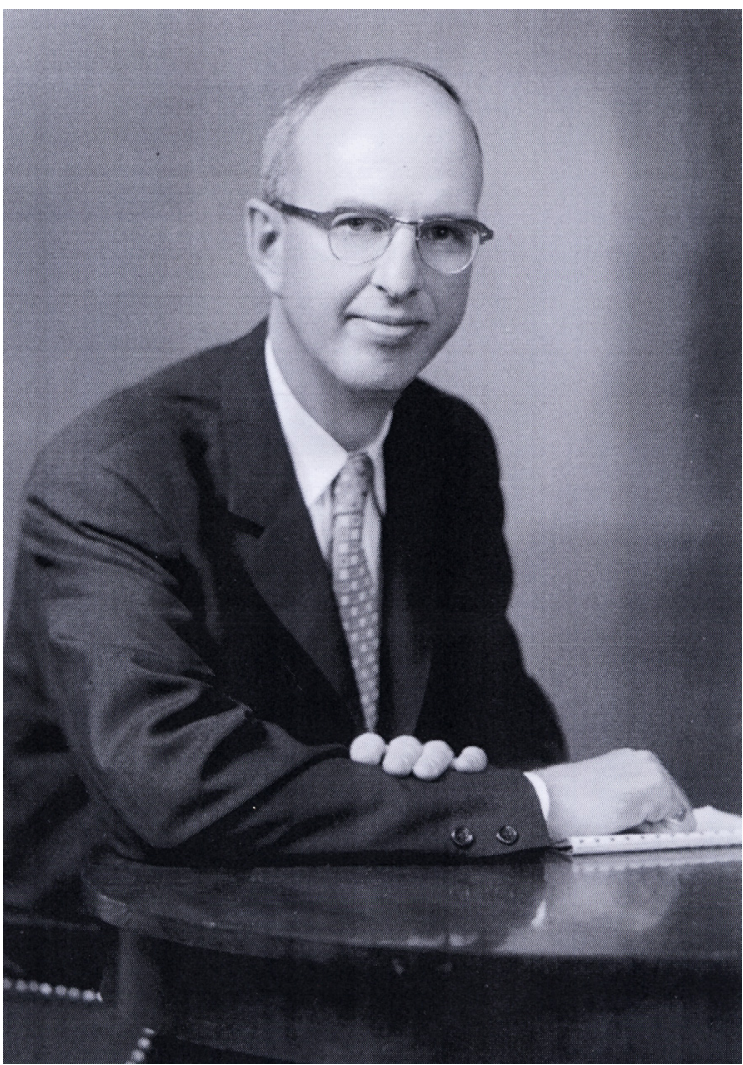

Fig. 9. Royal David Thomas Jr, Director of Research and Development of Arcos Corporation, then President of this Company (1958-1980). President of the American Welding Society during the 1960-1961 year (family collection, with permission).

the other engineers who stayed in the factory for production of military engines.

So, by the end of 1944, we can read in Arcos Dippings that Royal David Thomas Sr, wishing a happy new year to all families, recalled the effort to be done at each level of the company while recent news coming from the battle fields were showing that the war was far from being over, the American forces stuck by German resistance in the Vosges under cold conditions so that efforts were more and more necessary. He anticipated the future world of reconversion when peace would return, a reconversion that would impose new choices and more efforts. He insisted on the need to keep focused, while "our boys are riding their jeeps into liberated French towns," a true image at the time.

The last papers published in Arcos Dippings from the early 1945 to the end of the War give information about the events in the Pacific area and the final destruction of Hiroshima and Nagasaki: Arcos Dippings raises up the serious question about this new destructive force that will be necessary to control and keep peace. The question of "the perspective of new developments by the scientific progress is to look for new stainless steels application and for a better world," he said.

Royal David Thomas Jr became Executive VicePresident of the Arcos Company in January 1946. This 
industrial group extended its commercial influence to many States in the USA, and then to Hawaï, Mexico, Canada, Chili, and Perou. Staying as Director for the Reseach and Engineering Department, "Dave" prospected new countries, including Europe, and he made a visit in Switzerland in September 1948. In Zurich, he gave a lecture on the "Constitutional diagram applied to stainless steel welding" with a publication some months later [24]. In that lecture, he presented the know-how of the Arcos Company and the Schaeffler Diagram as a result of the team he had managed, together with his own contribution. He spoke about the chart that was presented in October the year before by Schaeffler at the annual Meeting of the AWS. He recalled the published papers prepared by himself with Campbell, particularly the interest of the chart for the prediction of the welded joint final mechanical properties. This lecture is important because it highlights some very general questions such as how to define the value to be taken for each element coefficients, the more or less ferromagnetic crystalline structures, the hydrogen embrittlement effect, the heat treatments that, in some temperature range, give sigma phase precipitation, thus introducing another brittleness factor. Royal David Thomas Jr finally addressed the ambiguous role played by the manganese additions and precisely gave rules for choosing electrodes composition for each application. In the discussions one can learn that the steels that had been used for some years for German tank ("Panzer") construction were more alloyed with manganese additions than the grades used for the US "M4 Sherman" armours. Let us recall that the manganese has an important pseudo-ferrite first effect, when ferrite phase is maintained in a non-equilibrium state in as-cast conditions. Royal David Thomas also spoke of the important role played by other factors such as electrodes with external coating, welding speed, space between electrode and plate, factors influencing the binding quality, etc.

Thus ended for the Arcos Company its first story with American Industry between 1939 and 1950, with a technical literature clearly still in its early infancy. The 2nd edition of the "Welding Metallurgy" book initially published in 1940 by Henry and Claussen for the Polytechnical Institute of Brooklyn in New York and revised in 1949 by G.E. Linnert from Armco Steel Corporation [7] shows the evolution of research after four years of terrible conflict "with an abnormally accelerated pace" all over the world. Yet the interest for the dilution direction for a welded structure between two different steels is only mentioned with a short presentation of an old diagram by Maurer and Monypenny's reference book. There is no concern in the book for the Arcos Company and the name of Schaeffler is given only once, with no reference.

Royal David Thomas Jr's career continued at the Arcos Company. He became its President in 1956 and President of AWS in 1960-1961. He retired from Arcos in 1980, keeping activities as consultant. He was the manager of different committees in the United States and in many World organisms. "Dave" received numerous honours, Fellow of the American Society for Metals and Price Winner of the Welding International Institution.
Royal David Thomas Jr died on March 4, 2008 at St Alban (Vermont State) at the age of 93.

\section{Conclusion}

When Tony Schaeffler prepared his now famous diagram in order to meet the imperious needs of Arcos Company at the end of World War II, he probably had little idea of its success and of the future development of his work.

His work became a big step and marked a new age for a wide range of technical applications in the steel welding processes. We mentioned the importance of basic research at the beginning of the 20th century by Strauß and Maurer for the first alloyed steels. We then observed a very slow evolution of scientific knowledge in contrast with the singular simple diagram conceived by Schaeffler and his team. His work was first applied for welding problems, and then enlarged in many applications for the steel industry.

We also insisted on the difficult context through which this study has been in progress and the high importance of the know-how of the Company in which Anton Schaeffler was employed and particularly the place of the two Royal David Thomas, Sr and Jr. It is too late now to give credit to other people and rename the Schaeffler diagram but it remains that the association of the three names "SchaefflerArcos-Thomas" would have a better historical signification.

One of us, P.G., thanks the late Royal David Thomas Jr for contacts and long correspondence during several years on this subject and for his permission to publish the frame and details corresponding to this history, pictures, original references and records of the American Welding Society. P.G. also thanks Mr David Null, working at Archives Service of Wisconsin University for access to the Memory of Anton Schaeffler for his Master degree. Both authors deeply thank Robert Alberny (past Secretary of SF2M, the French Society of Metallurgy and Materials, and current co-Editor-in-Chief of Materials Research \& Technology, formerly Revue de Métallurgie) for encouraging this historical reflection.

\section{References}

1. A. Schaeffler, Master Degree thesis, University of Wisconsin, No. 56-3036, 1944 (Archives \& Records Management Services, University of Wisconsin-Madison)

2. R.D. Thomas Jr, Arcos Deepings J. 4(1945), 5 (1946)

3. A. Schaeffler, Fellow nomination form, 1994 (American Welding Society Archives)

4. A. Schaeffler, Manuscript paper (AWS Archives) given by AWS to Royal David Thomas Jr, 1991

5. Milwaukee Journal Sentinel, 2001

6. A.B. Kinzel, R. Franks, The alloys of iron and chromium, vol. II High chromium alloys - Alloys of iron monographs (The Engineering Foundation, McGraw-Hill, New York, 1940)

7. O.H. Henry, G.E. Claussen, in Welding Metallurgy, 1st edn. (AWS, New York, 1940) (2nd edn. revised by G.E. Linnert (AWS, New York, 1949))

8. J.H.G. Monypenny, Stainless Iron and Steel (Chapman and Hall, London, 1926)

9. A.L. Schaeffler, Welding J. Res. Suppl., 610s (1947) 
10. B. Strauß, E. Maurer, Kruppsche Monatshefte 1, 129 (1920)

11. R. Scherer, G. Riedrich, G. Hoch, Arch. das Eisenhüttenwes., 53 (1939)

12. L. Guillet, Rev. Metall. 3, 243 (1906)

13. H.D. Newell, M. Fleischman, US Patent (1939) No. 2.118.683, 1938

14. R.D. Thomas Jr, Austenitic welding in Defense Equipement (Technical Publication Arcos Corp., Philadelphia, 1941)

15. H.C. Campbell, R.D. Thomas Jr, Welding J. Res. Suppl., 760s (1946)

16. K.W. Ostrom,R.D. Thomas Jr, Welding J. Res. Suppl., 1s (1941)
17. A.L. Field, F.K. Bloom, G.E. Linnert, Development of Armor welding electrodes: The effect of variation in chromium-nickel ratio and molybdenum content of austenitic (20 Cr-10 Ni) electrodes on properties of Armor Welments OSRD No. 3034 , 1943

18. A.L. Schaeffler, Iron Age 162, 72 (1948)

19. A.L. Schaeffler, Metal Progress, 680 (1949)

20. W.T. DeLong, Metal Progress, 98 (1960)

21. L. Pryce, K.W. Andrews, J. Iron Steel Inst., 415 (1960)

22. P. Guiraldenq, Mem. Sc. Rev. Metall. 11, 907 (1967)

23. M.C. Balmforth, J.C. Lippold, Welding J. Res. Suppl., 1s (1998)

24. R.D. Thomas Jr, Schweiz. Arch. angewandte Wiss. Tech. 1, 3 (1949)

Cite this article as: Pierre Guiraldenq, Olivier Hardouin Duparc, The genesis of the Schaeffler diagram in the history of stainless steel, Metall. Res. Technol. 114, 613 (2017) 